\title{
Integrating -Omics: Systems Biology as Explored Through C. elegans Research
}

\author{
Roel Van Assche ${ }^{1, \dagger}$, Valérie Broeckx ${ }^{1, \dagger}$, Kurt Boonen ${ }^{1}$, Evelyne Maes ${ }^{1,2}$, \\ Wouter De Haes ${ }^{1}$, Liliane Schoofs ${ }^{1}$ and Liesbet Temmerman ${ }^{1}$ \\ 1 - Functional Genomics and Proteomics, Department of Biology, KU Leuven Naamsestraat 59, 3000 Leuven, Belgium \\ 2 - Flemish Institute for Technological Research (VITO), Boeretang 200, 2400 Mol, Belgium
}

Correspondence to Liesbet Temmerman: Functional Genomics and Proteomics, Zoological Institute, Naamsestraat 59, 3000 Leuven, Belgium. liesbet.temmerman@bio.kuleuven.be

http://dx.doi.org/10.1016/j.jmb.2015.03.015

Edited by S. Koide

\begin{abstract}
-Omics data have become indispensable to systems biology, which aims to describe the full complexity of functional cells, tissues, organs and organisms. Generating vast amounts of data via such methods, researchers have invested in ways of handling and interpreting these. From the large volumes of -omics data that have been gathered over the years, it is clear that the information derived from one -ome is usually far from complete. Now, individual techniques and methods for integration are maturing to the point that researchers can focus on network-based integration rather than simply interpreting single -ome studies. This review evaluates the application of integrated -omics approaches with a focus on Caenorhabditis elegans studies, intending to direct researchers in this field to useful databases and inspiring examples.
\end{abstract}

(c) 2015 Elsevier Ltd. All rights reserved.

\section{Introduction}

Since the first whole genome (of the bacteria Haemophilus influenzae) was sequenced by Fleischmann et al. in 1995 [1], researchers increasingly recognized the informational wealth of largescale, high-throughput data. This meant the start of the development of multiple -omics fields, which focus on the presence or behavior of large groups of biomolecules of a kind within a sample. Nowadays, more than 30 -omics fields are described. Among these, genomics, transcriptomics, proteomics and metabolomics are the most mature and most studied ones. In addition, an increasing number of lesser known and more refined -omics fields, like epigenomics, secretomics, glycomics and lipidomics, have also come to the attention of researchers in biomedical and biological fields [2].

Data from different -omics studies are often categorized into three main types: components data, interactions data and data from functional states analyses (Fig. 1) [3]. Components data cover descriptive studies of a defined part of a biological sample. Genome annotation, transcriptome, prote- ome, metabolome, glycome and lipidome data-be it descriptive or differential-are just a few examples. This is in contrast to interactions data, in which the relationships between components within a sample are investigated. Two types are particularly popular here: protein-protein and protein-DNA interactions, in general referred to as interactomics studies. Such data provide important scaffolds for the elucidation of biological networks. The last category is more vaguely defined and describes the overall behavior or phenotype of a biological system. Fluxomics and phenomics studies belong to this class of -omics data [3].

-Omics approaches aim to address the multifactorial origins of biological systems or diseases by gathering data on as many targets as possible rather than "simply" looking for a few critical players within a single biological component. However, even at this scale, the information often comes in scattered bits and pieces [4-7]. This has led us to an increased interest in the integration of multiple complementary components, interactions or functional states datasets-a practice sometimes referred to as "integromics". It should be noted that, based on such elaborate 


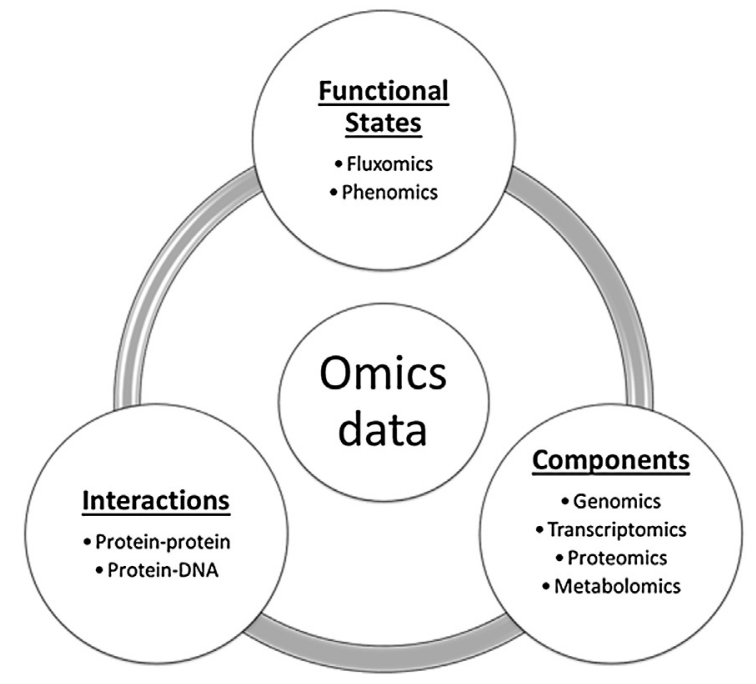

Fig. 1. General types of -omics data and examples (adapted from Ref. [3]).

information, the critical players often emerge as key nodes of complex biological networks [8-10]. Integration of the interactions between biological entities has evolved to the field of systems biology, wherein a holistic approach is used to understand complex biological systems. In this review, we summarize the recent advances in the field, focusing mainly on Caenorhabditis elegans research.

C. elegans is a small free-living roundworm, found primarily in environments rich in bacteria such as compost and rotting fruit [11]. Sydney Brenner introduced it in the 1960s for the study of its development and nervous system [12]. Praised by many as an ideal model organism due to the ease by which it can be reared in laboratory environments, C. elegans has provided a multitude of key insights into molecular biology (molecular mechanisms underlying RNAi) [13], central principles in cell biology (apoptosis as being essential to development [14]) and neurobiology (genetics of axonal guidance [15]). C. elegans was the first multicellular organism to have its genome sequenced [16], and extensive bioinformatics and genetic tools exist to facilitate research using this system. In addition to its relatively low complexity, many well-kept $C$. elegans -omics databases (Table 1) support its use in the study of complex molecular networks in systems biology. Especially in light of -omics studies, this nematode has multiple practical advantages for standardization of experiments (precise age synchronization, identical amount of cells, no unwanted influence of sex in hermaphrodite cultures and strict control over nutritional content). In this way, the introduction of undesirable experimental variation is kept to a bare minimum when compared to experiments with most other complex organisms.

\section{Why Integrate?}

Biological systems are neither static in time nor homogenous in spatial distribution [2]. Every -ome analysis represents a snapshot of the physiological state at the time the -ome is extracted. Beside differences inherent to the biology and biochemistry of each sample, the development of -omics methods strongly depends on the technical evolution of the instruments needed, each with their respective limitations. For example concerning transcriptomics studies, nucleic acid modifications and splice variants may not be observed, transcripts may fail to bind (or cross-hybridize with) microarray probes and RNAseq techniques encounter problems concerning coverage in repeat-rich regions. More downstream, enrichment methods for specific proteins are being developed [17], but no amplification method exists for these extracted molecules. Some efforts have already been made in $C$. elegans with co-immunoprecipitation of protein complexes to detect low abundant features [17]. However, in complex samples, low abundant features are hard to detect in mass spectrometry-based studies, not even mentioning that extraction methods only result in partial representation of the whole -ome. On top of that, the use of database-driven identification is limited to known database entries, often leading to lists of "interesting unknowns". This issue can be overcome, to some extent, using de novo methods, but these are time consuming and especially for metabolomics studies often put on the back burner.

Because each -omics field is characterized by its own strengths and weaknesses and is therefore bound to miss out on a part of the complexity of a biological system, a systems biology approach is usually based on the data integration of two or more -omes. The goal of integration is twofold: on the one hand, a more accurate picture of the behavior of one species of molecules is obtained, and on the other hand, a more holistic view of the system is achieved by looking at the behavior of multiple components (RNAs, proteins, etc.). This assists in the formulation of system-wide biological hypotheses. For example, Walhout et al. combined interactome, phenome and transcriptome data for the $C$. elegans germline and found that essential proteins have a tendency to interact with each other (phenome + interactome) and that pairs of genes encoding interacting proteins tend to exhibit similar expression profiles (interactome + transcriptome) [73].

In the quest for a complete description and annotation of a single -ome, different technical platforms are often combined. Such an approach has not yet been applied to $C$. elegans research, but valuable insights were delivered in a study focusing on $\mathrm{NCl}-60$ cancer cell line ovarian tumors [18]. Here, approximately half of all genes detected in the samples using four different transcriptomics 
Table 1. A collection of online available C. elegans -omics databases (adapted from [31]).

\begin{tabular}{|c|c|c|c|}
\hline Name database & URL & Information in database & Data category \\
\hline WormBase & www.wormbase.org/ & $\begin{array}{l}\text { Biology of } C \text {. elegans; central database } \\
\text { including a wide array of information } \\
\text { (e.g., expression, RNAi, ORFs, phenotypes, } \\
\text { interactions) }\end{array}$ & $\begin{array}{l}\text { Components data } \\
\text { Interactions data } \\
\text { Functional states data }\end{array}$ \\
\hline WORFDB & http://worfdb.dfci.harvard.edu/ & ORFeome of $C$. elegans & Components data \\
\hline $\begin{array}{l}\text { Hope Laboratory } \\
\text { Expression } \\
\text { Pattern Database }\end{array}$ & $\begin{array}{l}\text { http://worfdb.dfci.harvard.edu/ } \\
\text { promoteromedb/ }\end{array}$ & $\begin{array}{l}\text { PROMOTEROME of } C \text {. elegans (promoters } \\
\text { fused to GFP expression patterns) }\end{array}$ & Components data \\
\hline WormAtlas & http://www.wormatlas.org/ & Anatomy and behavior of $C$. elegans & $\begin{array}{l}\text { Components data } \\
\text { Interactions data } \\
\text { Functional states data }\end{array}$ \\
\hline Wormlmage & http://www.wormimage.org/ & Electron microscopy images of $C$. elegans & Components data \\
\hline $\begin{array}{l}\text { C. elegans Gene } \\
\text { Knockout } \\
\text { Consortium }\end{array}$ & http://celeganskoconsortium.omrf.org/ & Gene knockout strains & Functional states data \\
\hline RNAiDB & http://www.rnai.org/ & Phenotypes of many RNAi experiments & Functional states data \\
\hline PhenoBank & $\begin{array}{l}\text { http://www.worm.mpi-cbg.de/phenobank/ } \\
\text { cgi-bin/MenuPage.py }\end{array}$ & RNAi phenotypes & Functional states data \\
\hline
\end{tabular}

platforms were found in all datasets [18]. Such combinatory technical approaches are primarily popular in metabolomics research, where they ensure a broad coverage of the quite complex set of metabolites present in each sample $[19,20]$.

With the aforementioned limitations in mind, it is easy to understand that a combination of different techniques involves multiple advantages [5]. If the data share a common correlation over the different -omics analyses, the obtained results will be more robust compared to single -ome analysis. However, also less correlated identifiers can deliver new insights, for example, pointing toward post-transcriptional or post-translational regulation [21-23]. For example, if the amounts of proteins and transcripts are not correlated, some post-transcriptional regulation might be influencing the protein level data. Such discrepancies can lead to new insights in the regulation of certain genes. Additionally, certain identifiers are often missed at a single-ome dataset. These might yet be retrieved from a different biological entity to complement the set of biologically relevant information $[11,15]$. Combining multiple -omics data is therefore assumed to improve on pathway enrichment analyses [24].

\section{-Omics Data}

\section{Components data}

Components data are gathered with the intention of describing an organism's set of biomolecules as fully as possible. This may be under standard conditions [25], for specific conditions of interest [26] or in comparative studies $[20,27,28]$. Among these, differential components usually look at network changes under specific perturbations, such as the effect of drug compounds on the proteome of
C. elegans [29] or the effect of a toxic peptide on the metabolome of $C$. elegans [20]. The ease of working with $C$. elegans in the field of the systems biology is that, nowadays, many online databases collect subsets of the abundant $C$. elegans components data (Table 1), for example, WORFDB, a resource of all protein-encoding ORFs ${ }^{*}$ (open reading frames). Based on ORF predictions in databases such as WormBase $^{\S}$, up to 22,000 ORFs were verified [30] using sequencing-based methods (using expressed sequence tags and gateway clones) [31], which are now available through WORFDB. In addition, innumerate transcriptomics experiments have been performed in $C$. elegans [32-34]. Microarrays and serial analysis of gene expression are still popular, but the field is shifting to the use of the more sensitive RNA sequencing methods. These have been applied to whole transcriptome profiling, ribosomal profiling and RNA editing studies in C. elegans [35]. Once more, the use of a model system is emphasized for this sort of research as an advantage because of the availability of up-to-date gene annotations. An extension of the ENCODE project, ModENCODE, is a comprehensive encyclopedia of genomic "functional elements" of the model organisms $C$. elegans and Drosophila melanogaster. It provides access to abundant data on domains of gene structure, mRNA and non-coding RNA expression profiling; transcription factor binding sites; histone modifications and replacement; chromatin structure; DNA replication initiation and timing and so on [36]. These abovementioned databases are just a selection of the existing $C$. elegans databases (Table 1).

More downstream, both proteomics [28,29] and peptidomics (see $C$. elegans review [37]) are routinely used in $C$. elegans research. Nowadays, these are extended to more specialized analyses such as phosphoproteomics [38]. Data of these latter -omics 
fields can be found on platforms such as WormBase at this moment, but a user-friendly database in which all data are centralized is missing. At last, metabolomics, the youngest and most downstream -omics field, is starting to be used more frequently [20] in $C$. elegans research. Unfortunately, the $C$. elegans community lacks a proper platform with specific endogenous metabolites or related information.

\section{Interactions data}

Many biomolecules do not function as isolated entities but rather within complexes. Interactions data comprise information about interactions between molecular components (generally proteinprotein or DNA-protein interactions), often referred to as the interactome.

The interactomics field mainly revolves around protein data. This is because proteins are considered the central regulators of the biochemical reactions supporting organismal life and have a variety of functions (such as enzymatic, structural, storage, transport, transcription factor or immune system functions), which they tend to execute in complexes, either with DNA (e.g., transcription factors) or with other proteins. It should be noted that there is now a growing interest in functional non-coding RNAs as well; while their numbers are still debated, non-coding RNAs may direct transcription and translation (as reviewed by Shapiro [39] and Sabin et al. [40]).

Protein-protein interactions are often studied by yeast two-hybrid techniques in which researchers screen for interacting proteins in a high-throughput manner. Such an approach has helped uncover, for example, regulatory networks in the $C$. elegans DAF-7/TGF- $\beta$ signaling system [41]. Such $C$. elegans interactions data, including two high-throughput and large-scale yeast two-hybrid screens [42,43], can easily be consulted in the worm interactome database $^{\|}$[43].

Interactome data in $C$. elegans are not merely limited to protein-protein interactions. Many high-throughput DNA-protein interaction studies have been performed as well-typically using chromatin immunoprecipitation. Optimized methods for the global identification of transcription factor binding sites in $C$. elegans (through ChIPseq) are well-described in literature [44]. Chromatin-immunoprecipitation-based techniques have been used for the elucidation of other DNAprotein interactions as well, including interactions between modified histones and DNA to study epigenetic control of transcription and epigenetic inheritance in C. elegans [45-48].

One recent advancement in $C$. elegans interactomics is a method to directly identify non-coding micro-RNA target sites, paving the way for a better understanding of how the micro-RNAs act to alter cellular biology [49].

\section{Functional states data}

Functional states data comprise phenomics and fluxomics data. $C$. elegans has a well-characterized phenome that is built up from data often retrieved through high-throughput RNAi screens. These have been performed for nearly every protein-coding gene and a variety of phenotypes, of which the data are available in different databases (RNAiDB, PhenoBank and WormBase) [50]. The power of such screens and richness of data is demonstrated, for example, in a genome-wide RNAi screen for modifiers of polyglutamine aggregation in $C$. elegans [51]. Teuling et al. discovered 186 genes that suppress the polyglutamine aggregation process [51]. Starting from these data, a list of 26 homologous human genes was selected in order to further unravel the function concerning protein aggregation.

RNAi screens not only do predict the effect of an individual gene but could also provide information about interactions of functionally related proteins. For example, if some RNAi knockdowns result in a common phenotype, called a phenocluster, interactions can be predicted or novel protein functions can be discovered [31]. In this way, a somewhat focused list of candidate interaction partners can be proposed, which then need to be verified in great detail $[52,53]$. Many such screens are dependent on an automated analysis of the phenotype, which is essential to add robustness and sufficient throughput to these RNAi screens [54]. Some systems specific to $C$. elegans were developed to facilitate the automated detection of phenotype, often using locomotion as readout [55].

In addition to phenomes, $C$. elegans has also been used to generate fluxomics data. These studies often rely on the use of stable isotopes as markers to follow the dynamics and turnover of metabolic processes over time. Metabolic flux studies have been performed to evaluate metabolic responses to cadmium administration [56] or mitochondrial dysfunction [57] in C. elegans.

\section{Synergistic Effects of Combinatorial Analyses}

Although one single -omics dataset can yield clear biological insights, combination of multiple -omics data can lead to synergistic findings. To date, the most popular differential combinatorial analyses have relied on proteomics and transcriptomics experimental input. It is known that the correlation between mRNA and protein levels is insufficient to predict protein expression levels. Transcript and protein expression levels for selected genes expressed in the yeast Saccharomyces cerevisiae were determined [58]. These results showed a lack of a 1:1 correlation between mRNA and proteins and 
prompted researchers to combine both -omes in one analysis [5,58-65]. Experiments can be biased by methodological constrains and technical limitations, leading to a decreased mRNA-protein correlation [66]. Such low correspondence can be caused by several factors, such as post-transcriptional regulation that can account for up to $50 \%$ of the discordance between mRNA and protein quantities $[61,67]$. One example of such discrepancies can be found in a study evaluating the molecular effects of lifespan-extending interventions in $C$. elegans [21]. A direct correlation between mRNA and protein levels was observed for genes concerning S-adenosyl methionine synthesis, muscle-related proteins and branched-chain amino acid degradation. However, an increase in abundance of ribosomal subunits was observed in the proteomic analysis that was absent in the transcriptome. Although the differences between mRNA and protein levels can be due to technical limitations, in some cases, real biological insights can be obtained from comparative analysis of different -omics data (such as specific posttranscriptional regulation of ribosomal subunits in long-lived worms [21]).

Also, information from one -ome can be used to complete information of the other. An example of this is the field of proteogenomics, an area of research at the interface of proteomics and genomics. Here, proteomics data are used to identify and characterize novel protein-coding genes. Applications can be found in reading-frame determination, identification of gene and exon boundaries, evidence for posttranslational processing, identification of splice forms including alternative splicing and, also, prediction of completely novel genes [68]. Databases to facilitate proteogenomic analyses have been constructed using $C$. elegans RNAseq data [69]. These analyses in $C$. elegans improve the annotation of unknown genomic regions and provide information about splicing events in transcribed regions. Such methods can be especially helpful in the specific case of other species with poorly or unannotated genomes, where peptidomics or proteomics data can be matched to the unannotated genome to assist in further gene identification [70].

When multiple -omes are analyzed within one study, decisions need to be made on the way the emerging data will be treated. Integration can be performed in a rather naïve way by simply comparing the different outcomes from each -ome, but this can more aptly be executed with dedicated bioinformatics methods. While still less used due to their advanced nature, researchers are increasingly recognizing the value of such advanced statistical and bioinformatics approaches.

Also for $C$. elegans studies, the majority still relies on the naïve method mentioned above to combine multiple -omics datasets. Here, each -ome is analyzed separately (Fig. 2a) and the final combi- nation is performed in a post hoc manner [71]. For example, protein products of genes with similar expression patterns can be candidate interaction partners, as shown by research looking for DNA damage responses [72] and the fundamental germline biology [73]. Basic integration of $C$. elegans -omics data is also of value to drug screening: the genome and phenome of the worm have been used to screen for candidate drug targets in nematodes. This reduction in candidate target genes is expected to facilitate further screenings [74].

Pending a further evolution toward more complex integrative methods, researchers complement and compare individual experimental outcomes in meta-analyses to obtain a more complete view on their question of interest. This is demonstrated for -omics data regarding innate immunity in $C$. elegans [75] in which multiple studies subscribe the use of this model system to study protective responses against invading pathogens. Thanks to integration of these studies, some protein families (lectins, lysozymes, collagens and peptidases are just few examples) were discovered to play an important role in the immunity of $C$. elegans. These studies joined different data with the aim to find new insights, which is to a certain extent possible without relying on further bioinformatics interventions.

\section{Statistics and Bioinformatics Tools in -Omics Data Analysis and Integration}

Although direct comparative methods (Fig. 2a) are straightforward, they fail to integrate correlation or pathway information over the different -omes within a functional biological context. Therefore, analyses are shifting to more sophisticated approaches. For example, different molecular entities can be modeled using multivariate probability models (Fig. $2 b$ ). Since the measured effects in a single -ome dataset can be adjusted by data from other components, data incorporation from multiple molecular components can strengthen the statistical power. An even more elaborate integrating method relies on network-based integration (Fig. 2c), in which the simple one-to-one comparison of datasets is replaced by mapping all data onto molecular networks [71]. One such study relied on transcriptomics, protein-protein interaction and high-content phenotypic data $[42,76,77]$ to formulate a hypothesis of the molecular functioning of embryonic development in $C$. elegans [78]. Thanks to a dedicated computational method, a more reliable list of genes predicted to function in this network could be proposed for further in vivo verification.

Integration of -omics derived data is driven by mathematical models and computational tools to maximize the generation of complementary information [79]. Here, $C$. elegans researchers can rely on 
(a) Separated analysis
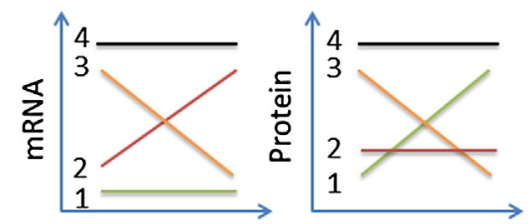

Merged data

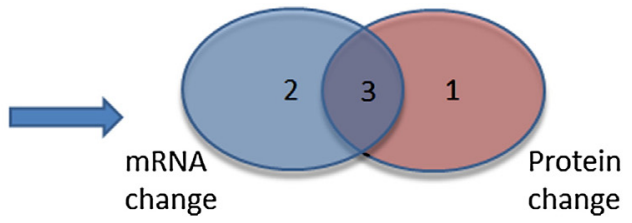

(b) Multivariate probability models (c) Network-based analysis
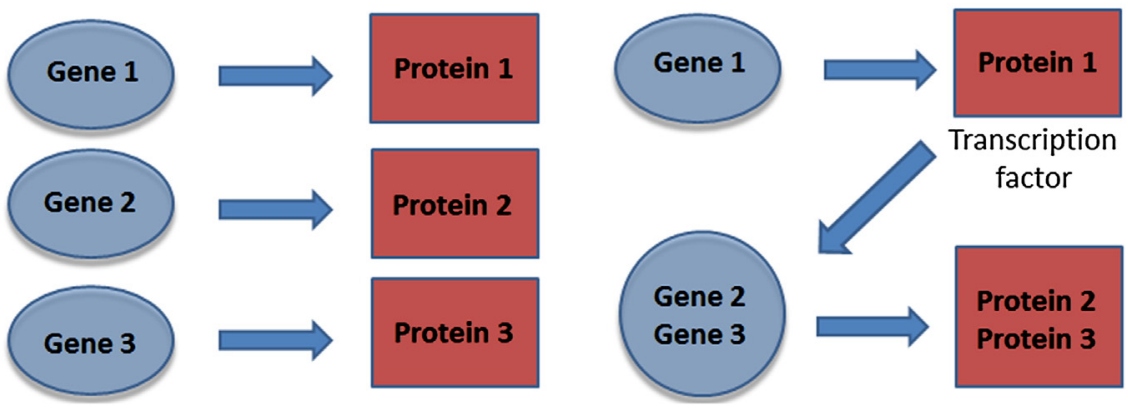

Fig. 2. The three most used methods for the integration of multiple -omics data [71].

efforts made by others within different organismal contexts. Any approach moving away from a simple data merging (Fig. 2a) showed to significantly increase on overlap between -omes and interesting target identification $[4,24,80]$. In this way, biological interpretation options increase significantly [71].

In order to overcome the mainly bioinformatics obstacles in such analyses, there are some software packages already available (Pointillist [81], 30mics [82], Paintomics [83] and KaPPA-View [84]). These packages (Table 2) can handle missing values and reconstruct the cellular network - it is therefore to be hoped that their use will increase in the $C$. elegans community, which is rich in data to support such analyses.

\section{Challenges and Future Perspectives}

Although integromics can be valuable to provide a more holistic overview of regulatory pathways within a biological system, many challenges still have to be overcome in order to produce unambiguous results. Main challenges are the inherent complexity of the biological systems, the lack of sufficient, proper bioinformatics tools and the large amounts of data [85].

One of the main characteristics of -omics research is the generation of huge asymmetric datasets. Although integration yields a lot more information, dealing with such "big data" remains an important challenge in statistical analysis. In addition, -omics data are prone to a high degree of variation, supported by the observation that different technical platforms within one -ome analysis usually result in widely varying data [24]. It is evident that this intra-ome variation impedes to some extent on the inter-ome integration. The primary data source can also impose technical challenges on integrative efforts: due to the different nature of diverse -omics platforms, differences in type of primary data format impede on a straightforward integration [22,24]. This can generally be overcome by converting raw data formats into a suitable format to ensure their successful import into integration software.

Furthermore, proper integromics analyses have to deal with the lack of common annotated names for corresponding compounds across the different -omes. For instance, it can be difficult to combine gene and protein names within one analysis, as these databases need to be linked to support functional network analysis. By converting the identifiers in representative gene names, Kohl et al. (2013) could link 50\% of the proteins to transcripts in patients suffering from hepatocellular carcinoma [86]. This is in contrast to less than $15 \%$ linking without conversion of the identifiers in representative gene names.

Depending on the hypothesis, it may suffice to use a targeted, single -ome approach. A part of the -omics field is moving toward hypothesis-driven -omics studies (asking how an intervention influences a specific biological pathway), which are not always in need of integrated approaches. In $C$. elegans research, targeted proteomics has been executed to validate predicted micro-RNA targets [87]. However, for those 
Table 2. An overview of software packages used for multiple -omics integration.

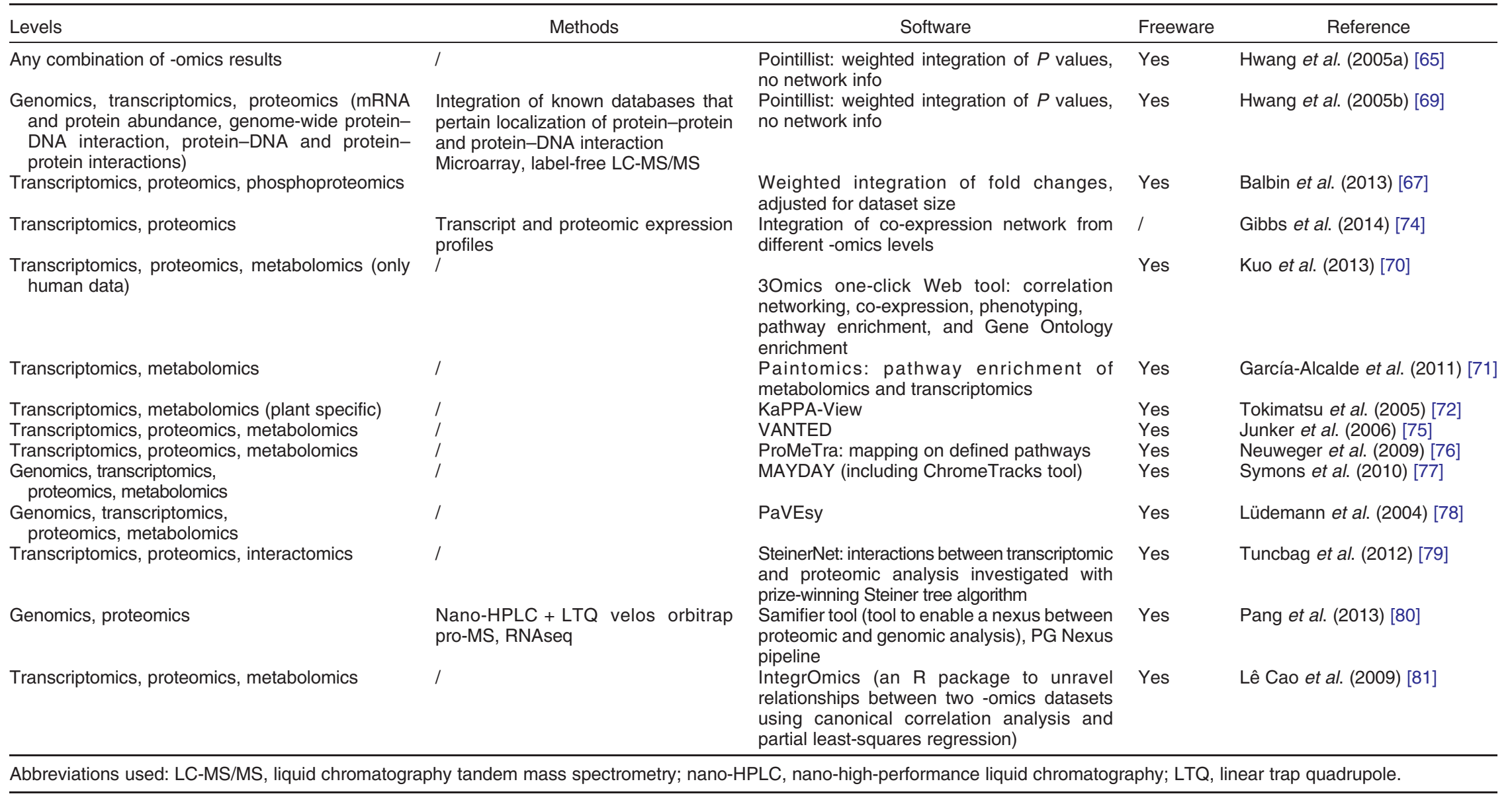


using -omics approaches in an exploratory, hypothesis-formulating way, it is to be expected that integrated -omics studies will become the golden standard, enabled by the rapidly growing technical evolutions in each of the -omics fields.

-Omics analyses will also become less expensive, an important factor in making combined analyses more accessible for many research teams. With the more recent development of single-cell analysis techniques [88], cellular heterogeneity - a common issue in systems biology-can be minimized. This exemplifies how (integrated) -omics techniques keep evolving at the forefront of science, and this continues to support innovative research.

\section{Conclusion}

Multiple components of complex biological systems can be studied using high-throughput -omics techniques. In addition, integration of the corresponding -omics data provides a more comprehensive overview of the full complexity of biological systems, formerly more difficult to unravel. The progress in bioinformatics solutions supports these systems biology approaches and demonstrates the potential of integrating multiple -omics data. C. elegans research benefits from several highquality and properly maintained -omics databases. As exemplified by a limited but valuable number of integrating -omics studies using this model system, we would like to encourage others in the field to consider such approaches for which they can rely on several bioinformatics tools enlisted in this review. While some challenges remain, implementation of integromics approaches in many fields in the future is a must.

\section{Acknowledgments}

Funding for this project was provided by Interuniversity Attraction Poles (IAP-P7/44). V.B. is an IWT Flanders research fellow. L.T. is an FWO-Flanders postdoctoral fellow. W.D.H. is funded by the KU Leuven Research Fund.

Received 24 December 2014; Received in revised form 24 March 2015; Accepted 25 March 2015 Available online $x x x x$

Keywords: systems biology; integrating -omics;
C. elegans

$\dagger$ R.V.A. and V.B. contributed equally to this work. + http://worfdb.dfci.harvard.edu/ $\S$ www.wormbase.org II http://interactome.dfci.harvard.edu/C_elegans/

\section{References}

[1] Fleischmann RD, Adams MD, White O, Clayton RA, Ewen F, Kerlavage AR, et al. Whole-genome random sequencing and assembly of Haemophilus influenzae Rd. Science 1995;496: $1-16$.

[2] Prohaska SJ, Stadler PF. The use and abuse of -omes. Methods Mol Biol 2011;719:173-96. http://dx.doi.org/10. 1007/978-1-61779-027-0_8.

[3] Cho WCS, editor. An Omics Perspective on Cancer Research. Dordrecht: Springer Netherlands; 2010. http://dx. doi.org/10.1007/978-90-481-2675-0.

[4] Balbin OA, Prensner JR, Sahu A, Yocum A, Shankar S, Malik $R$, et al. Reconstructing targetable pathways in lung cancer by integrating diverse omics data. Nat Commun 2013;4: 2617. http://dx.doi.org/10.1038/ncomms3617.

[5] Zhang W, Li F, Nie L. Integrating multiple "omics" analysis for microbial biology: application and methodologies. Microbiology 2010;156:287-301. http://dx.doi.org/10.1099/mic.0.034793-0.

[6] Tieri $P$, de la Fuente A, Termanini A, Franceschi C. Integrating omics data for signaling pathways, interactome reconstruction, and functional analysis. Methods Mol Biol 2011;719:415-33. http://dx.doi.org/10.1007/978-1-61779-027-0_19.

[7] De Keersmaecker SCJ, Thijs IMV, Vanderleyden J, Marchal K. Integration of omics data: how well does it work for bacteria? Mol Microbiol 2006;62:1239-50. http://dx.doi.org/ 10.1111/j.1365-2958.2006.05453.x.

[8] Schadt EE, Lum PY. Thematic review series: systems biology approaches to metabolic and cardiovascular disorders. Reverse engineering gene networks to identify key drivers of complex disease phenotypes. J Lipid Res 2006;47:2601-13. http://dx.doi.org/10.1194/jlr.R600026-JLR200.

[9] Hallock P, Thomas MA. Integrating the Alzheimer's disease proteome and transcriptome: a comprehensive network model of a complex disease. OMICS 2012;16:37-49. http:// dx.doi.org/10.1089/omi.2011.0054.

[10] Wang L, Xiao Y, Ping Y, Li J, Zhao H, Li F, et al. Integrating multi-omics for uncovering the architecture of cross-talking pathways in breast cancer. PLoS One 2014;9:e104282. http://dx.doi.org/10.1371/journal.pone.0104282.

[11] Kiontke KC, Félix M-A, Ailion M, Rockman MV, Braendle C, Pénigault J-B, et al. A phylogeny and molecular barcodes for Caenorhabditis, with numerous new species from rotting fruits. BMC Evol Biol 2011;11:339. http://dx.doi.org/10.1186/ 1471-2148-11-339.

[12] Brenner S. The genetics of Caenorhabditis elegans. Genetics 1974;77:71-94.

[13] Fire A, Xu S, Montgomery MK, Kostas SA, Driver SE, Mello CC. Potent and specific genetic interference by doublestranded RNA in Caenorhabditis elegans. Nature 1998;391: 806-11. http://dx.doi.org/10.1038/35888.

[14] Ellis RE, Yuan JY, Horvitz HR. Mechanisms and functions of cell death. Annu Rev Cell Biol 1991;7:663-98. http://dx.doi. org/10.1146/annurev.cb.07.110191.003311. 
[15] Zallen JA, Kirch SA, Bargmann Cl. Genes required for axon pathfinding and extension in the $C$. elegans nerve ring. Development 1999;126:3679-92.

[16] Hodgkin JC. C. elegans: sequence to biology. Science 1998; 282:2011. http://dx.doi.org/10.1126/science.282.5396.2011.

[17] Mass spectrometry-based shotgun proteomic analysis of C. elegans protein complexes. http://www.wormbook.org/ chapters/www_protcompanalysis/protcompanalysis.html. [accessed December 10, 2014].

[18] Shankavaram UT, Reinhold WC, Nishizuka S, Major S, Morita D, Chary KK, et al. Transcript and protein expression profiles of the $\mathrm{NCl}-60$ cancer cell panel: an integromic microarray study. Mol Cancer Ther 2007;6:820-32. http://dx. doi.org/10.1158/1535-7163.MCT-06-0650.

[19] Temmerman L, De Livera AM, Bowne JB, Sheedy JR, Callahan DL, Nahid A, et al. Cross-platform urine metabolomics of experimental hyperglycemia in type 2 diabetes. $J$ Diabetes Metab 2013;1. http://dx.doi.org/10.4172/21556156.S6-002.

[20] Van Assche R, Temmerman L, Dias DA, Boughton B, Boonen $\mathrm{K}$, Braeckman BP, et al. Metabolic profiling of a transgenic Caenorhabditis elegans Alzheimer model. Metabolomics 2015;11:477-86. http://dx.doi.org/10.1007/s11306-014-07115.

[21] Depuydt G, Xie F, Petyuk VA, Shanmugam N, Smolders A, Dhondt I, et al. Reduced insulin/insulin-like growth factor-1 signaling and dietary restriction inhibit translation but preserve muscle mass in Caenorhabditis elegans. Mol Cell Proteomics 2013;12:3624-39. http://dx.doi.org/10.1074/ mcp.M113.027383.

[22] Van lersel MP, Sokolović M, Lenaerts K, Kutmon M, Bouwman FG, Lamers WH, et al. Integrated visualization of a multi-omics study of starvation in mouse intestine. J Integr Bioinform 2014; 11:235. http://dx.doi.org/10.2390/biecoll-jib-2014-235.

[23] Ter Kuile BH, Westerhoff HV. Transcriptome meets metabolome: hierarchical and metabolic regulation of the glycolytic pathway. FEBS Lett 2001;500:169-71.

[24] Meng C, Kuster B, Culhane AC, Moghaddas Gholami A. A multivariate approach to the integration of multi-omics datasets. BMC Bioinformatics 2014;15:162. http://dx.doi. org/10.1186/1471-2105-15-162.

[25] Husson SJ, Clynen E, Baggerman G, De Loof A, Schoofs L. Discovering neuropeptides in Caenorhabditis elegans by two dimensional liquid chromatography and mass spectrometry. Biochem Biophys Res Commun 2005;335:76-86. http://dx. doi.org/10.1016/j.bbrc.2005.07.044.

[26] Husson SJ, Lindemans M, Janssen T, Schoofs L. Comparison of Caenorhabditis elegans NLP peptides with arthropod neuropeptides. Trends Parasitol 2009;25:171-81. http://dx. doi.org/10.1016/j.pt.2008.12.009.

[27] De Haes W, Frooninckx L, Van Assche R, Smolders A, Depuydt G, Billen J, et al. Metformin promotes lifespan through mitohormesis via the peroxiredoxin PRDX-2. Proc Natl Acad Sci 2014:1-9. http://dx.doi.org/10.1073/pnas. 1321776111.

[28] Bogaerts A, Beets I, Temmerman L, Schoofs L, Verleyen P. Proteome changes of Caenorhabditis elegans upon a Staphylococcus aureus infection. Biol Direct 2010;5:11. http://dx.doi.org/10.1186/1745-6150-5-11.

[29] De Haes W, Frooninckx L, Van Assche R, Smolders A, Depuydt G, Billen J, et al. Metformin promotes lifespan through mitohormesis via the peroxiredoxin PRDX-2. Proc Natl Acad Sci U S A 2014;111:E2501-9. http://dx.doi.org/10. 1073/pnas.1321776111.
[30] Lamesch P, Milstein S, Hao T, Rosenberg J, Li N, Sequerra $\mathrm{R}$, et al. C. elegans ORFeome version 3.1: increasing the coverage of ORFeome resources with improved gene predictions. Genome Res 2004;14:2064-9. http://dx.doi.org/ 10.1101/gr.2496804.

[31] Piano F, Gunsalus KC, Hill DE, Vidal M. C. elegans network biology: a beginning. WormBook 2006;1-20. http://dx.doi. org/10.1895/wormbook.1.118.1.

[32] Hashimshony T, Feder M, Levin M, Hall BK, Yanai I. Spatiotemporal transcriptomics reveals the evolutionary history of the endoderm germ layer. Nature 2014. http://dx. doi.org/10.1038/nature13996.

[33] Schwarz EM, Kato M, Sternberg PW. Functional transcriptomics of a migrating cell in Caenorhabditis elegans. Proc Natl Acad Sci U S A 2012;109:16246-51. http://dx.doi.org/10. 1073/pnas.1203045109.

[34] Pietsch K, Saul N, Swain SC, Menzel R, Steinberg CEW, Stürzenbaum SR. Meta-analysis of global transcriptomics suggests that conserved genetic pathways are responsible for quercetin and tannic acid mediated longevity in C. elegans. Front Genet 2012;3:48. http://dx.doi.org/10. 3389/fgene.2012.00048.

[35] Zhao H-Q, Zhang P, Gao H, He X, Dou Y, Huang AY, et al. Profiling the RNA editomes of wild-type $C$. elegans and ADAR mutants. Genome Res 2014. http://dx.doi.org/10. 1101/gr.176107.114.

[36] He K, Shao J, Zhao Z, Liu D. The comprehensive transcriptional analysis in Caenorhabditis elegans by integrating ChIP-seq and gene expression data. Genet Res (Camb) 2014;96:e005. http://dx.doi.org/10.1017/ S0016672314000081.

[37] Husson SJ, Reumer A, Temmerman L, De Haes W, Schoofs L, Mertens I, et al. Worm peptidomics. EuPA Open Proteomics 2014;3:280-90. http://dx.doi.org/10.1016/j. euprot.2014.04.005.

[38] Fredens J, Engholm-Keller K, Møller-Jensen J, Larsen MR, Færgeman NJ. Identification of novel protein functions and signaling mechanisms by genetics and quantitative phosphoproteomics in Caenorhabditis elegans. Methods Mol Biol 2014;1188:107-24. http://dx.doi.org/10.1007/978-1-49391142-4 9.

[39] Shapiro JA. Revisiting the central dogma in the 21st century. Ann N Y Acad Sci 2009;1178:6-28. http://dx.doi.org/10. 1111/j.1749-6632.2009.04990.x.

[40] Sabin LR, Delás MJ, Hannon GJ. Dogma derailed: the many influences of RNA on the genome. Mol Cell 2013;49:783-94. http://dx.doi.org/10.1016/j.molcel.2013.02.010.

[41] Tewari M, Hu PJ, Ahn JS, Ayivi-Guedehoussou N, Vidalain $\mathrm{P}-\mathrm{O}$, Li S, et al. Systematic interactome mapping and genetic perturbation analysis of a $C$. elegans TGF- $\beta$ signaling network. Mol Cell 2004;13:469-82. http://dx.doi.org/10. 1016/S1097-2765(04)00033-4.

[42] Li S, Armstrong CM, Bertin N, Ge H, Milstein S, Boxem M, et al. A map of the interactome network of the metazoan C. elegans. Science 2004;303:540-4.

[43] Simonis N, Rual J-F, Carvunis A-R, Tasan M, Lemmens I, Hirozane-Kishikawa $\mathrm{T}$, et al. Empirically controlled mapping of the Caenorhabditis elegans protein-protein interactome network. Nat Methods 2008;6:47-54. http://dx.doi.org/10. 1038/nmeth.1279.

[44] Brdlik CM, Niu W, Snyder M. Chromatin immunoprecipitation and multiplex sequencing (ChIP-Seq) to identify global transcription factor binding sites in the nematode Caenorhabditis elegans. Methods Enzymol 2014;539:89-111. 
[45] Rechtsteiner A, Ercan S, Takasaki T, Phippen TM, Egelhofer TA, Wang W, et al. The histone H3K36 methyltransferase MES-4 acts epigenetically to transmit the memory of germline gene expression to progeny. PLoS Genet 2010;6:e1001091. http://dx.doi.org/10.1371/journal.pgen.1001091.

[46] Greer EL, Maures TJ, Ucar D, Hauswirth AG, Mancini E, Lim $\mathrm{JP}$, et al. Transgenerational epigenetic inheritance of longevity in Caenorhabditis elegans. Nature 2011;479: 365-71. http://dx.doi.org/10.1038/nature10572.

[47] Meister P, Schott S, Bedet C, Xiao Y, Rohner S, Bodennec S, et al. Caenorhabditis elegans heterochromatin protein 1 (HPL-2) links developmental plasticity, longevity and lipid metabolism. Genome Biol 2011;12:R123. http://dx.doi.org/ 10.1186/gb-2011-12-12-r123.

[48] Castellano-Pozo M, Santos-Pereira JM, Rondón AG, Barroso S, Andújar E, Pérez-Alegre $\mathrm{M}$, et al. R loops are linked to histone H3 S10 phosphorylation and chromatin condensation. Mol Cell 2013;52:583-90. http://dx.doi.org/10. 1016/j.molcel.2013.10.006.

[49] Grosswendt S, Filipchyk A, Manzano M, Klironomos F, Schilling M, Herzog M, et al. Unambiguous identification of miRNA:target site interactions by different types of ligation reactions. Mol Cell 2014;54:1042-54. http://dx.doi.org/10. 1016/j.molcel.2014.03.049.

[50] Kamath RS, Fraser AG, Dong Y, Poulin G, Durbin R, Gotta M, et al. Systematic functional analysis of the Caenorhabditis elegans genome using RNAi. Nature 2003;421:231-7. http:// dx.doi.org/10.1038/nature01278.

[51] Teuling E, Bourgonje A, Veenje S, Thijssen K, de Boer J, van der Velde $\mathrm{J}$, et al. Modifiers of mutant huntingtin aggregation: functional conservation of $C$. elegans-modifiers of polyglutamine aggregation. PLoS Curr 2011;3:RRN1255. http://dx.doi. org/10.1371/currents.RRN1255.

[52] Piano F, Schetter AJ, Morton DG, Gunsalus KC, Reinke V, Kim $\mathrm{SK}$, et al. Gene clustering based on RNAi phenotypes of ovaryenriched genes in C. elegans. Curr Biol 2002;12:1959-64.

[53] Vidal M. A biological atlas of functional maps. Cell 2001;104: 333-9.

[54] Weirauch MT, Wong CK, Byrne AB, Stuart JM. Informationbased methods for predicting gene function from systematic gene knock-downs. BMC Bioinformatics 2008;9:463. http:// dx.doi.org/10.1186/1471-2105-9-463.

[55] Jung S-K, Aleman-Meza B, Riepe C, Zhong W. QuantWorm: a comprehensive software package for Caenorhabditis elegans phenotypic assays. PLoS One 2014;9:e84830. http://dx.doi.org/10.1371/journal.pone.0084830.

[56] Hughes SL, Bundy JG, Want EJ, Kille P, Stu SR. The metabolomic responses of Caenorhabditis elegans to cadmium are largely independent of metallothionein status, but dominated by changes in cystathionine and phytochelatins research articles. J Proteome Res 2009;8:3512-9.

[57] Schrier Vergano S, Rao M, McCormack S, Ostrovsky J, Clarke C, Preston J, et al. In vivo metabolic flux profiling with stable isotopes discriminates sites and quantifies effects of mitochondrial dysfunction in C. elegans. Mol Genet Metab 2014;111:331-41. http://dx.doi.org/10.1016/j.ymgme.2013. 12.011.

[58] Gygi SP, Rochon Y, Franza BR, Aebersold R. Correlation between protein and mRNA abundance in yeast. Mol Cell Biol 1999;19:1720-30.

[59] Lundberg E, Fagerberg L, Klevebring D, Matic I, Geiger T, Cox J, et al. Defining the transcriptome and proteome in three functionally different human cell lines. Mol Syst Biol 2010;6: 450. http://dx.doi.org/10.1038/msb.2010.106.
[60] Kohl M, Megger DA, Trippler M, Meckel H, Ahrens M, Bracht $\mathrm{T}$, et al. A practical data processing workflow for multi-OMICS projects. Biochim Biophys Acta 2014;1844:52-62. http://dx. doi.org/10.1016/j.bbapap.2013.02.029.

[61] Berghoff BA, Konzer A, Mank NN, Looso M, Rische T, Förstner KU, et al. Integrative "omics"-approach discovers dynamic and regulatory features of bacterial stress responses. PLoS Genet 2013;9:e1003576. http://dx.doi.org/ 10.1371/journal.pgen.1003576.

[62] Valgepea K, Adamberg K, Nahku R, Lahtvee P-J, Arike L, Vilu R. Systems biology approach reveals that overflow metabolism of acetate in Escherichia coli is triggered by carbon catabolite repression of acetyl-CoA synthetase. BMC Syst Biol 2010;4: 166. http://dx.doi.org/10.1186/1752-0509-4-166.

[63] Lahtvee P-J, Adamberg K, Arike L, Nahku R, Aller K, Vilu R. Multi-omics approach to study the growth efficiency and amino acid metabolism in Lactococcus lactis at various specific growth rates. Microb Cell Fact 2011;10:12. http://dx. doi.org/10.1186/1475-2859-10-12.

[64] Brockmann R, Beyer A, Heinisch JJ, Wilhelm T. Posttranscriptional expression regulation: what determines translation rates? PLoS Comput Biol 2007;3:e57. http://dx.doi.org/ 10.1371/journal.pcbi.0030057.

[65] Tian Q, Stepaniants SB, Mao M, Weng L, Feetham MC, Doyle $\mathrm{MJ}$, et al. Integrated genomic and proteomic analyses of gene expression in mammalian cells. Mol Cell Proteomics 2004;3: 960-9. http://dx.doi.org/10.1074/mcp. M400055-MCP200.

[66] Lu P, Vogel C, Wang R, Yao X, Marcotte EM. Absolute protein expression profiling estimates the relative contributions of transcriptional and translational regulation. Nat Biotechnol 2007;25:117-24. http://dx.doi.org/10.1038/nbt1270.

[67] Waters KM, Pounds JG, Thrall BD. Data merging for integrated microarray and proteomic analysis. Brief Funct Genomic Proteomic 2006;5:261-72. http://dx.doi.org/10. 1093/bfgp/ell019.

[68] Castellana N, Bafna V. Proteogenomics to discover the full coding content of genomes: a computational perspective. J Proteomics 2010;73:2124-35. http://dx.doi.org/10.1016/j. jprot.2010.06.007.

[69] Woo S, Cha SW, Merrihew G, He Y, Castellana N, Guest C, et al. Proteogenomic database construction driven from large scale RNA-seq data. J Proteome Res 2014;13:21-8. http:// dx.doi.org/10.1021/pr400294c.

[70] Robinson SD, Safavi-Hemami H, Raghuraman S, Imperial JS, Papenfuss AT, Teichert RW, et al. Discovery by proteogenomics and characterization of an RF-amide neuropeptide from cone snail venom. J Proteomics 2014;114C: 38-47. http://dx.doi.org/10.1016/j.jprot.2014.11.003.

[71] Choi H, Pavelka N. When one and one gives more than two: challenges and opportunities of integrative omics. Front Genet 2011;2:105. http://dx.doi.org/10.3389/fgene.2011.00105.

[72] Boulton SJ, Gartner A, Reboul J, Vaglio P, Dyson N, Hill DE, et al. Combined functional genomic maps of the $C$. elegans DNA damage response. Science 2002;295:127-31. http://dx. doi.org/10.1126/science.1065986.

[73] Walhout AJM, Reboul J, Shtanko O, Bertin N, Vaglio P, Ge H, et al. Integrating interactome, phenome, and transcriptome mapping data for the $C$. elegans germline. Curr Biol 2002;12: 1952-8.

[74] O'Reilly LP, Long OS, Cobanoglu MC, Benson JA, Luke CJ, Miedel MT, et al. A genome-wide RNAi screen identifies potential drug targets in a $C$. elegans model of $\alpha 1$-antitrypsin deficiency. Hum Mol Genet 2014;23:5123-32. http://dx.doi. org $/ 10.1093 / \mathrm{hmg} / \mathrm{ddu} 236$. 
[75] Simonsen KT, Gallego SF, Kallipolitis BH. Strength in Numbers; 2012 477-84.

[76] Kim SK, Lund J, Kiraly M, Duke K, Jiang M, Stuart JM, et al. A gene expression map for Caenorhabditis elegans. Science 2001;293:2087-92. http://dx.doi.org/10.1126/science.1061603.

[77] Sönnichsen B, Koski LB, Walsh A, Marschall P, Neumann B, Brehm M, et al. Full-genome RNAi profiling of early embryogenesis in Caenorhabditis elegans. Nature 2005; 434:462-9. http://dx.doi.org/10.1038/nature03353.

[78] Gunsalus KC, Ge H, Schetter AJ, Goldberg DS, Han J-DJ, Hao $\mathrm{T}$, et al. Predictive models of molecular machines involved in Caenorhabditis elegans early embryogenesis. Nature 2005;436:861-5. http://dx.doi.org/10.1038/ nature03876.

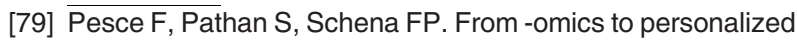
medicine in nephrology: integration is the key. Nephrol Dial Transplant 2013;28:24-8. http://dx.doi.org/10.1093/ndt/ gfs483.

[80] Gibbs DL, Gralinski L, Baric RS, McWeeney SK. Multi-omic network signatures of disease. Front Genet 2014;4:309. http://dx.doi.org/10.3389/fgene.2013.00309.

[81] Hwang D, Rust AG, Ramsey S, Smith JJ, Leslie DM, Weston $A D$, et al. A data integration methodology for systems biology. Proc Natl Acad Sci U S A 2005;102:17296-301. http://dx.doi.org/10.1073/pnas.0508647102.

[82] Kuo T-C, Tian T-F, Tseng YJ. 3Omics: a Web-based systems biology tool for analysis, integration and visualization of human transcriptomic, proteomic and metabolomic data.
BMC Syst Biol 2013;7:64. http://dx.doi.org/10.1186/17520509-7-64.

[83] García-Alcalde F, García-López F, Dopazo J, Conesa A. Paintomics: a Web based tool for the joint visualization of transcriptomics and metabolomics data. Bioinformatics 2011; 27:137-9. http://dx.doi.org/10.1093/bioinformatics/btq594.

[84] Tokimatsu T, Sakurai N, Suzuki H, Ohta H, Nishitani K. KaPPA-View. a Web-based analysis tool for integration of transcript and metabolite data on plant metabolic. Bioinformatics 2005;138:1289-300. http://dx.doi.org/10.1104/pp. 105.060525.1.

[85] Ghosh S, Matsuoka Y, Asai Y, Hsin K-Y, Kitano H. Software for systems biology: from tools to integrated platforms. Nat Rev Genet 2011;12:821-32. http://dx.doi.org/10.1038/ nrg3096.

[86] Kohl M, Megger DA, Trippler M, Meckel H, Ahrens M, Bracht $\mathrm{T}$, et al. A practical data processing workflow for multi-OMICS projects. Biochim Biophys Acta 1844;2014:52-62. http://dx. doi.org/10.1016/j.bbapap.2013.02.029.

[87] Jovanovic M, Reiter L, Picotti P, Lange V, Bogan E, Hurschler $\mathrm{BA}$, et al. A quantitative targeted proteomics approach to validate predicted microRNA targets in C. elegans. Nat Methods 2010;7:837-42. http://dx.doi.org/10.1038/nmeth. 1504.

[88] Wang D, Bodovitz S. Single cell analysis: the new frontier in "omics". Trends Biotechnol 2010;28:281-90. http://dx.doi. org/10.1016/j.tibtech.2010.03.002. 